\title{
Propileno-glicol ou monensina na dieta de vacas leiteiras no período de transição: saúde do úbere, produção e composição do leite
}

[Propylene glycol or monensin on diets of dairy cows during the transition period: udder health, milk yield and composition]

\author{
R.V. Sá Fortes ${ }^{1}$, M.A.T. Artunduaga ${ }^{1}$, A.U. Carvalho ${ }^{2}$, S.G. Coelho ${ }^{2 *}$, R.B. Reis ${ }^{2}$, A.M.Q. Lana $^{2}$ \\ ${ }^{1}$ Aluno de pós-graduação - Escola de Veterinária - UFMG \\ ${ }^{2}$ Escola de Veterinária - UFMG \\ Caixa Postal 567 \\ 30123-970 - Belo Horizonte, MG.
}

\begin{abstract}
RESUMO
Avaliou-se o efeito do propileno-glicol e da monensina na dieta de vacas leiteiras no período de transição sobre a produção e composição do leite. Foram utilizadas 42 vacas da raça Holandesa com média de produção na lactação anterior de $8.000 \mathrm{~kg}$. Os animais, distribuídos em sete tratamentos segundo um delineamento inteiramente ao acaso, receberam dietas basais pré e pós-parto ou dietas basais acrescidas com $300 \mathrm{ml}$ de propileno-glicol ou 30ppm de monensina sódica na matéria seca da dieta. Nos dias 10 e 20 pós-parto, avaliouse a produção de leite seguida de coleta de amostras para estudo dos constituintes do leite - gordura, proteína, lactose e extrato seco e de uréia e contagem de células somáticas. A inclusão de propileno-glicol apenas no período pós-parto resultou em diminuição da produção de leite e da quantidade total de gordura e proteína nos tempos de coleta estudados $(\mathrm{P}<0,05)$. A adição de propileno-glicol no pré-parto resultou em aumento da porcentagem de gordura, extrato seco e lactose nos tempos de coleta estudados $(\mathrm{P}<0,05)$. A inclusão de monensina tanto no pré quanto no pós-parto reduziu a porcentagem de proteína em relação aos outros tratamentos.
\end{abstract}

Palavras-chave: leite, produção composição, células somáticas, uréia

\begin{abstract}
The influence of the addition of propylene glycol or monensin to diets of dairy cows during the transition period on milk production and milk composition was studied. Forty-two multiparous Holstein cows with an average milk production of $8,000 \mathrm{~kg}$ in the previous lactation were distributed in a complete randomized design and were divided into seven groups receiving either control diets or diets with 30ppm of monensin or $300 \mathrm{ml}$ of propylene glycol during the transition period. Milk production was recorded on days $10^{\text {th }}$ and $20^{\text {th }}$ post-partum and milk samples were taken on the same days to analyse milk components such as fat, protein, lactose, urea and somatic cells $\left(10^{\mathrm{l}} / \mathrm{ml}\right)$. The addition of propylene glycol in the post-partum diet decreased milk production as well as total the fat and protein production on the sampling times (days $10^{\text {th }}$ and $20^{\text {th }}$ postpartum) $(P<0.05)$. The adition of propylene glycol during pre-partum increased fat and lactose percentage on the sampling times $(P<0.05)$. The use of monensin during pre and post-partum periods decreased the protein percentage.
\end{abstract}

Keywords: milk yield, milk composition, protein, somatic cells, urea

\section{INTRODUÇÃO}

A constante busca por equilíbrio entre a receita, por meio da produção de leite, e o custeio da atividade leiteira faz com que o produtor e o técnico sempre procurem alternativas para que os animais tenham sucesso no período de transição. Essa é uma fase crítica para a saúde da vaca

Recebido em 8 de novembro de 2007

Aceito em 31 de janeiro de 2008

*Autor para correspondência (corresponding author)

E-mail: sandra@vet.ufmg.br

Apoio: FAPEMIG 
leiteira que pode interferir em toda lactação, reduzindo a quantidade de leite produzido, aumentando os gastos e, principalmente, afetando a rentabilidade da atividade.

Segundo Grummer (1995), o período de transição corresponde às três semanas pré e às três semanas pós-parto, sendo esse período, fim da gestação e início da lactação, marcado por grandes mudanças hormonais e metabólicas, as quais estão quase sempre associadas à diminuição da ingestão de alimentos (matéria seca) e balanço energético negativo, que, por sua vez, vai predispor a maior incidência de problemas metabólicos com conseqüente queda na produção de leite (Dann et al., 1999).

O período de transição é o momento de maior risco para o aparecimento de doenças metabólicas e infecciosas. Aproximadamente $75 \%$ das doenças ocorrem no primeiro mês após o parto, sendo as doenças metabólicas as mais freqüentes e altamente relacionadas ao manejo nutricional e às mudanças preparatórias para o parto (LeBlanc, 2006). Dessa forma, esse período tem grande impacto econômico na exploração leiteira.

Na tentativa de minimizar os efeitos do balanço energético negativo durante o período de transição e suas conseqüências sobre a saúde e produção animal, é necessário aumentar a ingestão de energia pelos animais nessa fase da vida produtiva (Lucy et al., 1991). O uso de aditivos gliconeogênicos pode ser uma forma de melhorar o balanço energético quando usados na dieta durante o período de transição. Dentre os aditivos gliconeogênicos mais utilizados destacam-se o propileno-glicol e os ionóforos (monensina).

O volume de leite produzido é principal fator para pagamento desse produto. No entanto, esse quadro vem sofrendo rápidas alterações e a qualidade passa a ter maior peso na composição do preço do leite mensurada pela qualidade sanitária e nutricional do leite.

Este trabalho teve como objetivo avaliar os efeitos dos aditivos gliconeogênicos (propilenoglicol ou monensina) fornecidos nas dietas durante o período de transição sobre a produção e composição do leite e saúde do úbere.

\section{MATERIAL E MÉTODOS}

Foram utilizadas 42 vacas da raça Holandesa, no período de 28 dias antes da data prevista do parto até o $21^{\circ}$ dia pós-parto. Os animais utilizados produziram na lactação anterior média de $8.000 \mathrm{~kg}$ de leite. No período pré-parto, os animais foram distribuídos em três grupos e, no período pós-parto, redistribuídos em sete grupos (Fig. 1). Os constituintes da dieta-controle são apresentados na Tab. 1. Todas as dietas foram formuladas para atender as exigências nutricionais no pré e no pós-parto, segundo Nutrient... (2001).

Os animais foram estabulados em baias do tipo tie stall e confinados 28 dias antes da data prevista do parto. $\mathrm{O}$ fornecimento dos aditivos iniciou-se aos 21 dias antes da data de parto prevista, a monensina sódica foi fornecida como parte da ração total e o propileno-glicol foi adicionado a $1,0 \mathrm{~kg}$ de silagem de grão úmido de milho e colocado sobre a dieta. Todos os tratamentos foram mantidos até o $21^{\circ}$ dia de lactação, quando todos os animais foram confinados no sistema tipo free stall.

As pesagens e as coletas de amostras de leite foram realizadas no $10^{\circ}$ e $11^{\circ}$ e no $20^{\circ}$ e $21^{\circ}$ dias pós-parto. A produção de leite foi mensurada e corrigida para 3,5\% (LCG 3,5\%) de gordura utilizando a fórmula sugerida por Gravet (1996).

Amostras de $50 \mathrm{ml}$ de leite foram acondicionadas em recipientes contendo conservante bromopol (2-bromo 2-nitropropano 1,3-diol), na proporção de $10 \mathrm{mg}$ do principio ativo para $50 \mathrm{ml}$ de leite, e armazenadas entre $4-6^{\circ} \mathrm{C}$ para posterior análise. A determinação das porcentagens de extrato seco total e desengordurado, proteína total, gordura, lactose e a contagem de células somáticas foram feitas com o uso da metodologia eletrônica Bentley ${ }^{\circledR}$. Os teores de nitrogênio não protéico do leite foram obtidos pelo método do ácido tricloroacético segundo AOAC (Official.., 1980). 


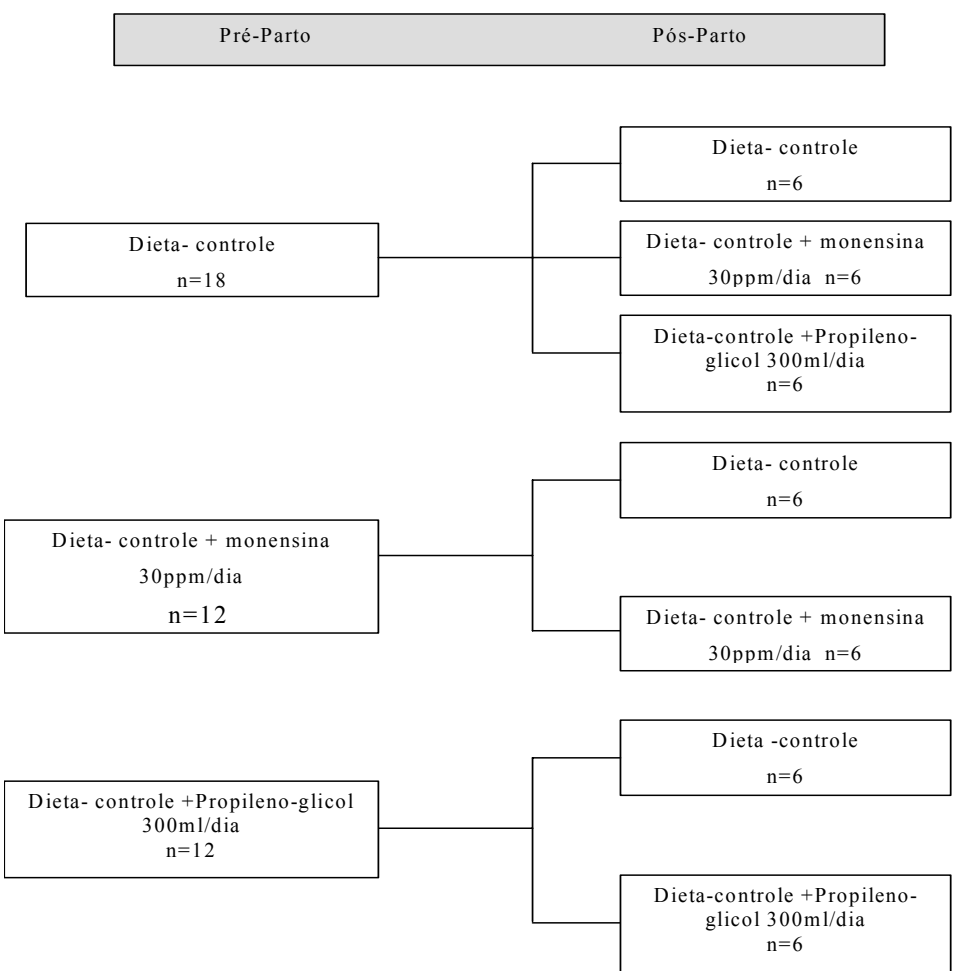

Figura 1. Alimentação de vacas leiteiras no pré e pós-parto conforme o delineamento experimental.

Tabela 1. Constituintes das dietas controle pré e pós-parto, utilizados nas dietas base no período experimental

\begin{tabular}{|c|c|c|}
\hline & \multicolumn{2}{|c|}{ Dieta basal } \\
\hline & Pré-parto & Pós-parto \\
\hline \multicolumn{3}{|l|}{ Ingrediente, $\%$ na matéria seca } \\
\hline Silagem de milho & 61,03 & 30,80 \\
\hline Feno & 4,30 & 4,60 \\
\hline Silagem de grão úmido de milho & 6,70 & 19,60 \\
\hline Caroço de algodão & 1,80 & 9,60 \\
\hline Polpa cítrica & 8,60 & 11,50 \\
\hline Farelo de soja & 13,70 & 18,30 \\
\hline Uréia & ----- & 0,50 \\
\hline Premix min.-vit. $\mathrm{A}^{1}$ & 3,80 & ---- \\
\hline Premix min.-vit. $\mathrm{B}^{2}$ & ---- & 4,90 \\
\hline \multicolumn{3}{|l|}{ Nutriente, \% na matéria seca } \\
\hline MS & 45,20 & 58,00 \\
\hline PB & 13,50 & 17,80 \\
\hline PNDR & 5,10 & 7,10 \\
\hline PDR & 8,40 & 10,70 \\
\hline FDN & 37,40 & 28,90 \\
\hline FDA & 22,40 & 21,10 \\
\hline $\mathrm{CNF}$ & 37,50 & 40,70 \\
\hline $\mathrm{Ca}$ & 0,70 & 1,10 \\
\hline $\mathrm{P}$ & 0,30 & 0,50 \\
\hline $\mathrm{Mg}$ & 1,00 & 2,95 \\
\hline $\mathrm{K}$ & --- & 0,75 \\
\hline \multicolumn{3}{|c|}{ 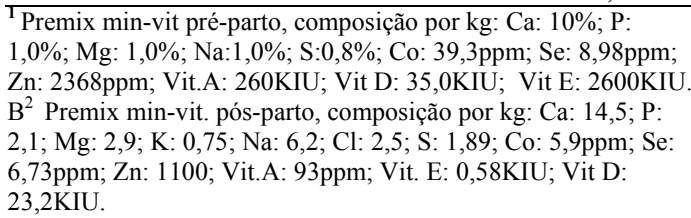 } \\
\hline
\end{tabular}

Usou-se delineamento inteiramente ao acaso. Para avaliar as variáveis produção total de leite, gordura, proteína, lactose, extrato seco desengordurado, uréia e contagem de células somáticas, usou-se o teste Lilliefors para verificação de normalidade e Cochran e Bartlett para verificação de homogeneidade. Aplicaramse a análise de variância e o teste Duncan $(\mathrm{P}<0,05)$ para a comparação de médias entre tratamentos e tempos de coleta. Para a variável contagem das células somáticas (CCS), foi realizada uma transformação logarítmica em base decimal $(\log (\mathrm{CCS}))$. Para avaliação de escore de condição corporal, foi utilizado o teste não paramétrico Kruskal-Wallis $(\mathrm{P}<0,05)$. Os dados foram analisados utilizando-se o SAEG (Sistemas..., 1998).

\section{RESULTADOS E DISCUSSÃO}

Os dados de produção de leite, porcentagem de gordura, gordura total, porcentagem de proteína, proteína total, porcentagem de lactose, extrato seco total, uréia e contagem de células somáticas podem ser observados na Tab. 2 . 
Tabela 2. Médias da produção $(\mathrm{kg})$ e dos componentes do leite - gordura, proteína, lactose e extrato seco e de uréia e contagem de células somáticas, de acordo com os tratamentos e tempos de avaliação (dias)

\begin{tabular}{|c|c|c|c|c|c|c|c|c|c|c|c|c|c|c|}
\hline & \multicolumn{2}{|c|}{ CON-CON } & \multicolumn{2}{|c|}{ CON-MON } & \multicolumn{2}{|c|}{ CON-PG } & \multicolumn{2}{|c|}{ MON-CON } & \multicolumn{2}{|c|}{ MON-MON } & \multicolumn{2}{|c|}{ PG-CON } & \multicolumn{2}{|c|}{ PG-PG } \\
\hline & 10 & 20 & 10 & 20 & 10 & 20 & 10 & 20 & 10 & 20 & 10 & 20 & 10 & 20 \\
\hline Prod & 27,76 & 25,94 & 24,62 & 21,84 & 23,56 & 17,78 & 26,94 & 23,52 & 23,02 & 23,02 & 22,50 & 23,90 & 27,60 & 26,04 \\
\hline$(\mathrm{kg})$ & Aa & $\mathrm{Aa}$ & Aa & Aa & Aa & $\mathrm{Ab}$ & $\mathrm{Aa}$ & $\mathrm{Aa}$ & Aa & Aa & Aa & $\mathrm{Aa}$ & Aa & Aa \\
\hline Gord & 3,89 & 3,56 & 4,79 & 3,51 & 4,33 & 4,44 & 3,95 & 3,57 & 4,19 & 4,36 & 4,74 & 3,68 & 4,43 & 3,98 \\
\hline$(\%)$ & $\mathrm{Aa}$ & $\mathrm{Aa}$ & $\mathrm{Aa}$ & $\mathrm{Ab}$ & $\mathrm{Aa}$ & $\mathrm{Aa}$ & $\mathrm{Aa}$ & $\mathrm{Aa}$ & $\mathrm{Aa}$ & $\mathrm{Aa}$ & $\mathrm{Aa}$ & $\mathrm{Ab}$ & $\mathrm{Aa}$ & $\mathrm{Aa}$ \\
\hline Gord & 972 & 908 & 862 & 765 & 825 & 622 & 943 & 823 & 806 & 805 & 787 & 836 & 966 & 911 \\
\hline (g) & $\mathrm{Aa}$ & $\mathrm{Aa}$ & $\mathrm{Aa}$ & $\mathrm{Aa}$ & $\mathrm{Aa}$ & $\mathrm{Ab}$ & $\mathrm{Aa}$ & $\mathrm{Aa}$ & $\mathrm{Aa}$ & $\mathrm{Aa}$ & $\mathrm{Aa}$ & $\mathrm{Aa}$ & $\mathrm{Aa}$ & $\mathrm{Aa}$ \\
\hline Prot & 3,24 & 2,97 & 3,25 & 2,89 & 3,06 & 2,90 & 3,30 & 2,94 & 2,86 & 2,84 & 3,25 & 3,00 & 3,15 & 2,95 \\
\hline (\%) & $\mathrm{ABa}$ & $\mathrm{Aa}$ & $\mathrm{ABa}$ & $\mathrm{Ab}$ & Aba & $\mathrm{Aa}$ & $\mathrm{Aa}$ & $\mathrm{Ab}$ & $\mathrm{Ba}$ & $\mathrm{Aa}$ & $\mathrm{ABa}$ & $\mathrm{Aa}$ & $\mathrm{ABa}$ & $\mathrm{Aa}$ \\
\hline Prot & 891 & 763 & 793 & 635 & 704 & 503 & 846 & 694 & 699 & 642 & 734 & 709 & 870 & 762 \\
\hline (g) & $\mathrm{Aa}$ & $\mathrm{Aa}$ & $\mathrm{Aa}$ & $\mathrm{Aa}$ & $\mathrm{Aa}$ & $\mathrm{Ab}$ & $\mathrm{Aa}$ & $\mathrm{Aa}$ & $\mathrm{Aa}$ & $\mathrm{Aa}$ & $\mathrm{Aa}$ & $\mathrm{Aa}$ & $\mathrm{Aa}$ & $\mathrm{Aa}$ \\
\hline $\mathrm{Lac}$ & 4,47 & 4,55 & 4,20 & 4,46 & 4,46 & 4,67 & 4,51 & 4,64 & 4,41 & 4,33 & 4,43 & 4,72 & 4,55 & 4,70 \\
\hline$(\%)$ & $\mathrm{Aa}$ & $\mathrm{Aa}$ & $\mathrm{Ab}$ & $\mathrm{Aa}$ & $\mathrm{Aa}$ & $\mathrm{Aa}$ & $\mathrm{Aa}$ & $\mathrm{Aa}$ & $\mathrm{Aa}$ & $\mathrm{Aa}$ & $\mathrm{Ab}$ & $\mathrm{Aa}$ & $\mathrm{Aa}$ & $\mathrm{Aa}$ \\
\hline \multirow[t]{2}{*}{$\mathrm{ES}(\%)$} & 12,60 & 12,17 & 13,25 & 11,82 & 12,78 & 12,81 & 12,83 & 12,18 & 12,49 & 12,43 & 13,41 & 12,42 & 13,11 & 12,69 \\
\hline & $\mathrm{Aa}$ & $\mathrm{Aa}$ & $\mathrm{Aa}$ & $\mathrm{Ab}$ & $\mathrm{Aa}$ & $\mathrm{Aa}$ & $\mathrm{Aa}$ & $\mathrm{Aa}$ & $\mathrm{Aa}$ & $\mathrm{Aa}$ & $\mathrm{Aa}$ & $\mathrm{Ab}$ & $\mathrm{Aa}$ & Aa \\
\hline \multirow{4}{*}{$\begin{array}{l}\text { Uréia } \\
\text { (mg/dl) } \\
\text { CCS }\end{array}$} & 14,49 & 14,75 & 14,65 & 14,10 & 15,10 & 14,15 & 15,47 & 17,88 & 12,69 & 14,12 & 14,11 & 15,91 & 14,87 & 17,21 \\
\hline & Aa & Aa & Aa & Aa & Aa & $\mathrm{Aa}$ & Aa & Aa & Aa & Aa & $\mathrm{Aa}$ & Aa & Aa & Aa \\
\hline & 268,92 & 173,54 & 463,50 & 525,54 & 708,12 & 596,96 & 210,96 & 173,42 & 357,08 & 576,63 & 333,92 & 220,80 & 583,79 & 426,38 \\
\hline & $\mathrm{Aa}$ & $\mathrm{Aa}$ & $\mathrm{Aa}$ & $\mathrm{Aa}$ & $\mathrm{Aa}$ & $\mathrm{Aa}$ & $\mathrm{Aa}$ & $\mathrm{Aa}$ & $\mathrm{Aa}$ & $\mathrm{Aa}$ & $\mathrm{Aa}$ & $\mathrm{Aa}$ & $\mathrm{Aa}$ & $\mathrm{Aa}$ \\
\hline
\end{tabular}

Médias seguidas de letras distintas minúsculas indicam valores diferentes entre os dias de colheita, e médias seguidas de letras distintas maiúsculas indicam valores diferentes entre os tratamentos: teste Duncan $(\mathrm{P}<0,05)$.

PROD: produção de leite; GORD: gordura; PROT: proteína; LAC: lactose; ES: extrato seco; CCS: contagem de células somáticas; $\mathrm{CON}-\mathrm{CON}$ : grupo controle-controle; CON-MON: grupo controle-monensina; CON-PG: grupo controle-propileno-glicol; MONCON: grupo monensina-controle; MON-MON: grupo monensina-monensina; PG -CON: grupo propileno-glicol-controle; PG -PG: grupo propileno-glicol-propileno-glicol.

Com exceção do tratamento controle préparto/propileno-glicol pós-parto, os resultados referentes à produção de leite corrigida para $3,5 \%$ de gordura não apresentaram diferença $(\mathrm{P}>0,05)$ entre os tratamentos e entre os dois tempos de coleta (dias 10 e 20 pós-parto). O tratamento controle pré-parto/propileno-glicol pós-parto mostrou queda $(\mathrm{P}<0,05)$ na média de produção de leite entre os dois tempos de coleta e redução na produção total de gordura e proteína nos primeiros 21 dias de lactação. Os animais do tratamento controle pré-parto/monensina pósparto apresentaram um menor teor de gordura entre os dias 10 e 20 de lactação $(\mathrm{P}<0,05)$.

O teor médio de proteína do leite nas três primeiras semanas de lactação para os animais que receberam monensina no pré e pós-parto foi menor $(\mathrm{P}<0,05)$ que o observado no tratamento monensina pré-parto/controle pós-parto. Os outros tratamentos apresentaram teores de proteína semelhantes. Por outro lado, a produção de proteína total não acompanhou a tendência anteriormente mencionada, embora diferenças numéricas sejam observadas entre os tratamentos. Os animais do tratamento controle pré-parto/propileno-glicol pós-parto mostraram diferença $(\mathrm{P}<0,05)$ na produção total de proteína entre os tempos de coleta.

Quanto à porcentagem de lactose, extrato seco e uréia, não houve diferença $(\mathrm{P}>0,05)$ entre os tratamentos. Os tratamentos controle préparto/monensina pós-parto e propileno-glicol pré-parto/controle pós-parto apresentaram menores porcentagens de lactose $(\mathrm{P}<0,05)$ aos 10 dias de lactação e menor $(\mathrm{P}<0,05)$ porcentagem de extrato seco aos 20 dias de lactação.

As médias de contagem de células somáticas não foram diferentes $(\mathrm{P}>0,05)$ entre os tratamentos. Também não houve diferença significativa entre os tempos de coleta para a contagem de células somáticas. A tendência descrita anteriormente acompanha a ausência de casos clínicos de mastite durante o experimento.

Os valores médios para o escore da condição corporal para os diferentes tratamentos são apresentados na Tab. 3. 
Propileno-glicol ou monensina...

Tabela 3. Médias do escore da condição corporal de vacas leiteiras em função do tratamento e do dia de avaliação

\begin{tabular}{lcccccc}
\hline \multirow{2}{*}{ Tratamento } & \multicolumn{7}{c}{ Dia de avaliação } \\
\cline { 2 - 7 } & -21 & 0 & 7 & 14 & 21 & Perda (0 a 21dias) \\
\hline CON-CON & 4,0 & 3,9 & 3,2 & 2,9 & 2,8 & $-1,2$ \\
CON-MON & 3,7 & 3,7 & 2,9 & 2,5 & 2,5 & $-1,2$ \\
CON-PG & 3,9 & 3,8 & 3,1 & 2,5 & 2,5 & $-1,4$ \\
MON-CON & 3,7 & 3,7 & 2,9 & 2,5 & 2,5 & $-1,2$ \\
MON-MON & 4,1 & 4,0 & 3,0 & 2,6 & 2,6 & $-1,5$ \\
PG-CON & 3,6 & 3,6 & 2,9 & 2,5 & 2,5 & $-1,1$ \\
PG-PG & 3,7 & 3,7 & 3,1 & 2,9 & 2,9 & $-0,8$ \\
\hline
\end{tabular}

Médias comparadas pelo teste Kruskal-Wallis $(\mathrm{P}<0,05)$.

CON-CON: tratamento controle-controle; CON-MON: tratamento controle-monensina; CON-PG: tratamento controle-propilenoglicol; MON-CON: tratamento monensina-controle; MON-MON: tratamento monensina-monensina; PG-CON: tratamento propileno-glicol-controle; PG-PG: tratamento propileno-glicol-propileno-glicol.

Não houve efeito $(\mathrm{P}>0,05)$ da monensina sódica ou do propileno-glicol no período de transição sobre o escore da condição corporal, embora o tratamento com propileno-glicol préparto/propileno-glicol pós-parto tenha resultado em perda de pontos na escala do ECC de somente 0,8 pontos entre o parto e os 21 dias da lactação e o tratamento com monensina pré e pós-parto tenha apresentado perda de pontos na escala do ECC de 1,5.

$\mathrm{O}$ tratamento monensina pré-parto/monensina pós-parto resultou em menor $(\mathrm{P}<0,05)$ porcentagem de proteína $(2,9 \%)$ que o tratamento monensina pré-parto/controle pósparto, $(3,3 \%)$, no dia 10 de coleta (Tab. 1). Este resultado, associado à pequena variação ocorrida no ECC entre os dois tratamentos, sugere a hipótese de essa queda ser devido à maior mobilização das reservas corporais no tratamento monensina pré-parto - controle pós-parto, levando ao aumento de beta hidroxibutirato (BHBA) e de ácidos graxos não esterificados. Essa elevação pode ter provocado aumento na utilização de aminoácidos gliconeogênicos, reduzindo, dessa forma, a disponibilidade desses aminoácidos para a glândula mamária, provocando a queda no teor de proteína no leite (Rennó et al., 2006).

A queda da condição corporal no tratamento monensina pré e pós-parto pode ser atribuída à queda no consumo de matéria seca desse tratamento, provocada pela inclusão da monensina no pré e pós-parto.

Nos dois tempos de avaliação, 10 e 20 dias, não foram observadas diferenças $(\mathrm{P}>0,05)$ na produção de leite, nas porcentagens e quantidades de gordura e proteína, nas porcentagens de lactose e extrato seco, na quantidade de uréia e na CCS entre os tratamentos controle pré e pós-parto e propilenoglicol pré e pós-parto.

A menor produção de leite, gordura e proteína foi observada no tratamento controle préparto/propileno-glicol pós-parto $(\mathrm{P}<0,05)$, aos 20 dias de lactação. Essa queda na produção de leite não era esperada, uma vez que a utilização do propileno-glicol disponibilizaria mais substrato gliconeogênico, levando, conseqüentemente, maior aporte de glicose para a glândula mamária, aumentado a produção de leite. Czerkawski e Breckenridge (1973) propuseram uma rota de utilização do propileno-glicol pela microbiota ruminal similar à proposta para a utilização de rhamnose. Nessa rota, o propileno-glicol poderia produzir lactaldeído que resultaria na produção de lactato. A produção de lactato poderia provocar um quadro de acidose subclínica que resultaria na queda da produção de leite. A tabela de escore da condição corporal mostra, nesse tratamento, uma queda de 0,7 unidade de ECC do parto ao $7^{\circ}$ dia da lactação e uma queda de 0,6 unidade do dia sete ao dia 21 , sugerindo que, aos 21 dias da lactação, esse tratamento apresentava tendência em manter uma perda mais acentuada de ECC que os outros tratamentos. Isso evidenciaria alguma alteração que estava comprometendo a produção de leite e a condição corporal. Uma outra hipótese para queda na produção de leite e do ECC seria devido ao menor consumo de alimentos pelos animais desse tratamento. As hipóteses levantadas acima não podem ser confirmadas pela ausência de dados de consumo de alimentos e parâmetros sangüíneos. 
No tratamento controle pré-parto/monensina pósparto, as porcentagens de gordura, proteína e extrato seco total foram mais baixas, e de lactose mais alta $(\mathrm{P}<0,05)$, aos 20 dias de lactação. Essas alterações na composição do leite podem estar associadas à maior adaptação da microbiota ruminal aos 20 dias de lactação, com alteração na relação acetato: propionato, a favor do propionato, provocando queda no teor de gordura, pela menor disponibilização de acetato e butirato à glândula mamaria, e aumento no teor de lactose, pela maior disponibilização de glicose para a glândula mamária. A queda no teor de proteína pode ter sido ocasionada pela menor disponibilidade de aminoácidos para a glândula mamária, conforme hipótese postulada para o tratamento monensina pré-parto/monensina pósparto. O aumento no teor de lactose não foi capaz de compensar a queda no extrato seco provocada pela diminuição no teor de gordura.

O tratamento propileno-glicol pré-parto/controle pós-parto resultou em menores porcentagens de gordura e de extrato seco e maior de lactose $(\mathrm{P}<0,05)$, aos 20 dias de lactação. A queda na porcentagem de gordura talvez seja apenas conseqüência da menor mobilização de gordura corporal, refletida pela variação do ECC nessa fase, com menor disponibilização de ácidos graxos de cadeia longa para a glândula mamária. A queda no extrato seco foi provocada pela queda na gordura.

É importante lembrar que todas as características de composição do leite, avaliadas variaram dentro dos limites estabelecidos como normais. Pode-se dizer que apenas a proteína esteve um pouco abaixo dos valores relatados na literatura e que talvez isso seja um reflexo da pequena seleção para essa característica na raça Holandesa, no Brasil.

Nos dias atuais, a tentativa de mudar a composição do leite por meio da dieta é um fato, no entanto não é possível uma grande alteração de seus componentes, exceto para a gordura. Esta é a mais fácil de ser alterada quando há disponibilidade de forragens de boa qualidade e ausência de qualquer tipo de problemas metabólicos ou digestivos. Os outros componentes sofrem pequenas mudanças causadas pela fase da lactação ou por mudanças na dieta. Uma mudança significativa da proteína depende de um trabalho de seleção genética em longo prazo.

\section{REFERÊNCIAS BIBLIOGRÁFICAS}

CZERKAWISK, J.W.; BREKCKERINDGE, G. Dissimilation of 1,2-propanediol by rumen micro-organisms. Br. J. Nutr., v.29, p.317-330, 1973.

DANN, H.M.; VARGA, G.A.; PUTMAN, D.E. Improving energy supply to late gestation and early postpartum dairy cows. J. Dairy Sci., v.82, p.1765-1778, 1999.

GRAVET, H.O. Breeding of dairy cattle. In: Dairy cattle production. New York: Elsevier Science, 1996. p.35-76.

GRUMMER, R.R. Impact of changes organic nutrient metabolism on feeding the transition dairy cow. J. Dairy Sci., v.73, p.2820-2833, 1995.

LUCY, M.C.; STAPLES, C.R.; MICHEL, F.M. et al. Energy balance and number of ovarian follicles detected by ultrasonography in early post-partum dairy cows. J. Dairy Sci., v.74, p.473-482, 1991.

LeBLANC, S.J.; LISSEMORE, K.D.; KELTON, D.F. et. al. Major advances in disease prevention in dairy cattle. J. Dairy Sci., v.89, p.1267-1279, 2006.

NUTRIENT requirements of dairy cattle. 7.ed. Washington DC: National Academy of Sciences, 2001.

OFFICIAL methods of analysis. 13.ed. Washington, DC: AOAC, 1980. 1015p.

RENNÓ, F.P.; PEREIRA, J.C.; SANTOS, A.D.F. Efeito da condição corporal ao parto sobre a produção e composição do leite, a curva de lactação e a mobilização de reservas corporais em vacas da raça Holandesa. Arq. Bras. Med. Vet. Zootec., v.58, p.220-233, 2006.

SISTEMAS de análises estatísticas e genéticas SAEG. Versão 7.0. Viçosa: UFV, 1998. 